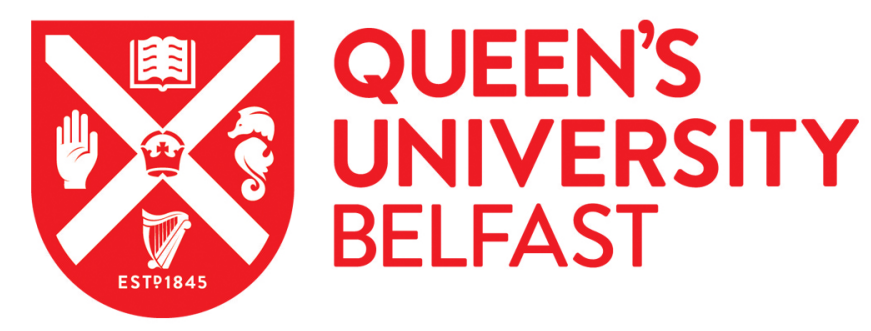

\title{
Gain and Efficiency Analysis of 2-Stage Switched Capacitor (SC) Boost Based dc-dc Converter
}

Rahim, N. A., Amir, A., El Khateb, A., Che, H. S., \& Amir, A. (2018). Gain and Efficiency Analysis of 2-Stage Switched Capacitor (SC) Boost Based dc-dc Converter. In 4th IET International Conference on Clean Energy and Technology (CEAT 2016): Proceedings IET. https://doi.org/10.1049/cp.2016.1312

Published in:

4th IET International Conference on Clean Energy and Technology (CEAT 2016): Proceedings

\section{Document Version:}

Peer reviewed version

\section{Queen's University Belfast - Research Portal:}

Link to publication record in Queen's University Belfast Research Portal

\section{Publisher rights}

(c) 2016 IEEE.

This work is made available online in accordance with the publisher's policies. Please refer to any applicable terms of use of the publisher.

\section{General rights}

Copyright for the publications made accessible via the Queen's University Belfast Research Portal is retained by the author(s) and / or other copyright owners and it is a condition of accessing these publications that users recognise and abide by the legal requirements associated with these rights.

Take down policy

The Research Portal is Queen's institutional repository that provides access to Queen's research output. Every effort has been made to ensure that content in the Research Portal does not infringe any person's rights, or applicable UK laws. If you discover content in the Research Portal that you believe breaches copyright or violates any law, please contact openaccess@qub.ac.uk. 


\title{
Gain and Efficiency Analysis of 2-Stage Switched Capacitor (SC) Boost Based dc-dc Converter
}

\author{
N A Rahim*', Asim Amir*, A. El Khateb*, Hang Seng Che*, Aamir Amir* \\ * Power Energy Dedicated Advanced Centre (UMPEDAC), Level 4, Wisma R\&D, University of Malaya, Jalan Pantai Baharu, \\ 59990 Kuala Lumpur, Malaysia, ${ }^{\dagger}$ Renewable Energy Research Group, King Abdulaziz University, Jeddah 21589, Saudi \\ Arabia, ${ }^{1}$ Corresponding author: nasrudin@um.edu.my.
}

Keywords: Switched capacitor (SC), continuous conduction mode (CCM), wide input voltage variation, High step up gain.

\begin{abstract}
This paper presents the theoretical analysis, operating principles, and comparison between basic boost and 2-stage switched capacitor (SC) based boost converter. Using voltsecond balance and current charge principle, voltage gain and efficiency are theoretically derived for the basic boost and 2stage SC based boost converter. MATLAB software has been utilized to simulate the predicted results. Simulation results, which are in complete agreement with the predicted results, have been analysed and compared with the results of the basic boost converter. Largely increased voltage gain with a commendable efficiency for the 2-stage SC based boost converter, validate the authenticity of the proposed system.
\end{abstract}

\section{Introduction}

High gain voltage boosting is favourable in applications such as renewable energy systems, uninterruptible power supplies (UPS), motor drives etc., where high output voltages are required from low voltage energy sources like batteries, fuel cells and photovoltaic (PV) panels. For instance, a PV panel typically outputs $15-45 \mathrm{~V}_{\mathrm{dc}}$, but a $\mathrm{PV}$ inverter requires around $380 \mathrm{~V}_{\mathrm{dc}}$ in order to generate $230 \mathrm{~V}_{\mathrm{rms}}$ for a singlephase grid. As a solution, dc-dc converter is needed to step up the insufficient input source voltage to 375-400 V [1-7]. Such $\mathrm{dc}-\mathrm{dc}$ converter can be an isolated or a non-isolated converter. Isolated dc-dc converters can be utilized to step up to the required voltage, using high voltage transformer (HVT). In such case, there are two basic techniques to obtain a high voltage gain. First is by increasing the turns ratio of the HVT; and second is to use voltage multiplier circuits on the secondary side of HVT [8-11]. Zero-voltage (ZVS) and (ZCS) Zero-current switching can be easily achieved using the leakage inductance of the HVT in full-bridge converters based on phase-shift pulse width modulation (PWM) control technique [12]. However, HVT with high turns ratio is unattractive for the reason that it magnifies voltage and current spikes in the transformer secondary side, the voltage stress across the output diode becomes much higher than the output voltage, and demands the use of diodes with high breakdown voltage [13]. Moreover, leakage inductance of the transformer induces high circulating current in the primary side, which can possibly, decrease the functional life of PV modules [12], hence large electrolytic capacitors are required to prevent input current ripple, which will increase size and cost of the converter. Consequently, all the disadvantages mentioned associated with isolated converters decrease its overall efficiency $[12,14,15]$.

On the other hand, non-isolated dc-dc converter, such as the basic boost converter, suffers from the drawback of high voltage stress on the switch and diode, which are equal to the output voltage, discouraging its implementation in high voltage applications. Moreover, this problem leads to a condition of employing active components with high voltage and diode with fast reverse recovery, effectively, contributing to higher cost. Furthermore, even though the output voltage can theoretically approach infinity, this cannot be achieved experimentally due to the parasitic resistive elements in the converter. Subsequently, some researchers proposed the use of switched capacitor (SC) circuits with basic boost converter to further boost the voltage gain [16]. Nevertheless, the impacts of parasitic elements, which can still affect the practical attainable voltage gain and efficiency of the SCbased boost converter, remain to be investigated.

This paper hence presents a theoretical analysis of a 2 stage SC boost based dc-dc converter and the basic boost converter. Moreover, voltage gain and efficiency of both the converters are compared using inductor volt-second balance and capacitor charge balance principle in CCM.

\section{Basic boost converter}

The structure of a basic boost converter is shown in Fig. 1. In order to analyze the gain and efficiency, it is necessary to take into in account the presence of the parasitic elements as seen in Fig. 2.

Theoretically, the basic boost converter can be analyzed by utilizing the volt-second balance and current charge balance principles in continuous conduction mode (CCM) of operation.

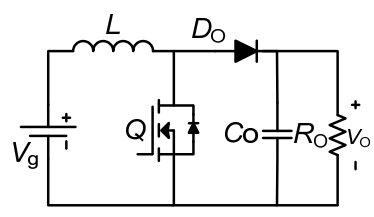

Fig. 1: Basic boost converter. 


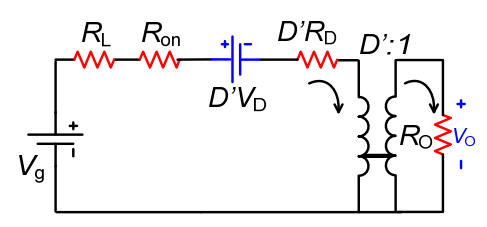

Fig. 2: Basic boost converter equivalent circuit considering parasitic resistive elements.

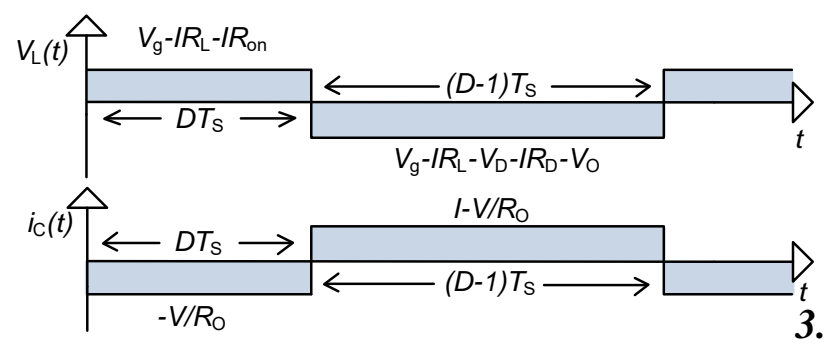

Fig. 3: Waveforms of inductor voltage and capacitor current in $\mathrm{CCM}$ for basic boost converter.

As observed in Fig. 3. Volt-second balance and current charge balance of the basic boost converter are given as (1) and (2) respectively:

$$
\begin{aligned}
& \left\langle V_{L}\right\rangle=D\left(V g-I R_{L}-I R_{O}\right)+(1-D)\left(V g-I R_{L}-V D-I R_{D}-V_{O}\right)=0 \\
& \left\langle i_{C}\right\rangle=D .\left(V / R_{O}\right)+(1-D) .\left(I-V / R_{O}\right)=0
\end{aligned}
$$

where $V_{\mathrm{o}}$ is the output voltage, $V_{\mathrm{g}}$ is the input voltage, $R_{\mathrm{o}}$ is the load resistance and $D$ is the duty cycle. Here non-ideal inherent resistive elements corresponding to the series inductor $R_{\mathrm{L}}$, switch $R_{\mathrm{on}}$, diode resistance $R_{\mathrm{D}}$ and diode threshold voltage $V_{\mathrm{D}}$ have also been considered, as shown in Fig. 2. Moreover,

$$
\begin{aligned}
& V_{g}-I R_{L}-I D R_{O n}-(1-D) \cdot V_{D^{-I}}-I(D-1) R_{D^{-}}(1-D) \cdot V_{O}=0 \\
& I(1-D)-\left(V_{O} / R_{O}\right)=0
\end{aligned}
$$

It is easy to demonstrate that the static gain $M=V_{o} / V_{g}$ is given by [17]:

$$
M=\frac{V_{O}}{V_{g}}=\left(\frac{1}{(1-D)}\right) \cdot\left(1-\frac{(1-D) V_{D}}{V_{g}}\right) \cdot\left(\frac{1}{1+\frac{R_{L}+D R_{O n}+(1-D) R_{D}}{(1-D)^{2} \cdot R_{O}}}\right)
$$

Theoretical efficiency of the boost converter, given by $\eta$, can be estimated by the following expression [17]:

$$
\begin{aligned}
& \eta=(1-D) \frac{V_{O}}{V g} \\
& \eta=\left(\frac{\left(1-\frac{(1-D) V D}{V g}\right)}{1+\frac{R_{L}+D R_{O n}+(1-D) R D}{(1-D)^{2} \cdot R_{O}}}\right)
\end{aligned}
$$

\section{2-stage switched capacitor boost based dc-dc converter}

The 2-stage SC boost based converter is derived from the basic boost converter by introducing a 2-stage SC cell as voltage doubler [18], as seen in Fig. 4. Here, SC cell allows the boost converter to achieve higher output voltage for the same duty cycle as for basic boost converter.

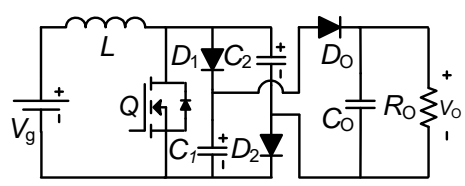

Fig. 4: 2-stage SC based boost converter[18].

\section{Operation of 2-stage switched capacitor boost based dc-dc converter}

When the inductor current is continuous, there are two operating modes for the converter. Figure 5 (c) shows the key waveforms of the converter, where $V_{\mathrm{gs}}$ is the driving signal of the switch; $V C_{1}$ and $V C_{2}$ are the voltages of capacitors $C_{1}$ and $C_{2}$, respectively and $i_{\mathrm{L}}$ is the current of the inductor. During time $\left[t_{0}-t_{1}\right]$ : switch $Q$ is conducting and the input voltage source charges $L$. At this point in time, $C_{2}$ and $C_{1}$ are connected in series to supply the load through $Q$ as presented in Fig. 5 (a). Thus, the voltage across the series combination of $C_{2}$ and $C_{1}$ decreases by a half. During time $\left[t_{1}-T_{\mathrm{S}}\right]$, the switch is turned off, such that $L$ charges $C_{2}$ and $C_{1}$ via $D_{1}$ and $D_{2}$ respectively as shown in Fig. 5 (b).

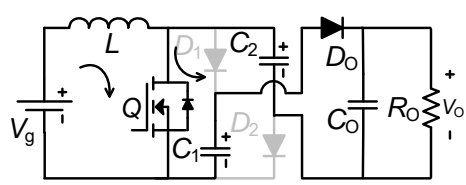

(a)

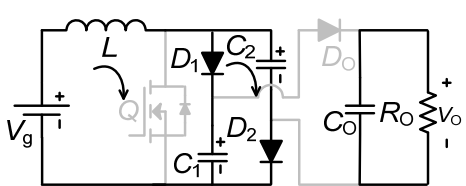

(b)

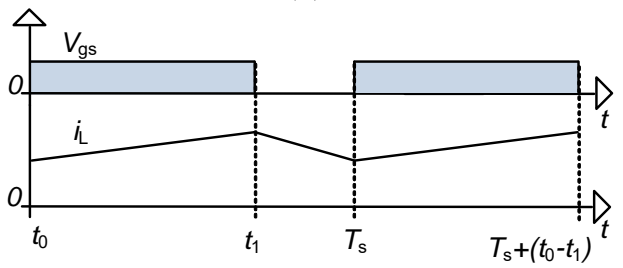

(c)

Fig. 5: (a) current flow when switch on state, (b). current flow when switch off state, (c). Steady state waveform inductor in CCM operation. 


\subsection{Analysis of 2-stage switched capacitor boost based dc-dc converter}

2-Stage SC boost converter has been employed for high conversion gain and efficiency. Figure 6 and 7 show the equivalent circuit models during switch on and off time, respectively. Here, the parasitic resistive elements have also been considered as depicted in Fig.7. During the on state, voltage is supplied to the load through the series connected capacitors $C_{1}, C_{2}$ where $V C_{1}=V C_{2}$. With the capacitor connected in series, half of the total output voltage, $V_{\mathrm{O}} / 2$ drops across the capacitors, whereas, the other half is supplied to the load. Observing Fig. 6, voltage drop across $R_{\text {on }}$ and $R_{\mathrm{D} 1}$ and $R_{\mathrm{D} 2}$ cancel out each other's effect due to opposite polarities. Fig. 7 illustrates the equivalent circuit model for Fig. 5 (b) during off time $\left[t_{1}-T_{\mathrm{S}}\right]$. During the off time, voltage is supplied to the load through $C_{\mathrm{o}}$. In addition, capacitors $C_{1}$, $C_{2}$ are charged in a parallel fashion, through the inductor $R_{\mathrm{L}}$. As observed, voltage across the parallel combination of capacitors $V C_{1}+V C_{2}$ in the voltage loop of Fig. 7 is equal to the voltage across output capacitor, $V C_{0}$.

$V C_{1}+V C_{2}=V C_{o}$

Figure 8 presents the on time and off time inductor voltage and capacitor current equation. The volt-second balance $\left\langle v_{L}\right\rangle$ and current charge balance $\left\langle_{i_{C}}\right\rangle$ of the 2-stage SC boost based dc-dc converter are given by:

$\left\langle V_{L}\right\rangle=D \cdot\left(V g-I R_{L}-I R_{O}\right)+(1-D) \cdot\left(V_{g}-I R_{L}-2 V_{D}-2 I R_{D}-V_{o} / 2\right)=0$

$\left\langle{ }_{i}\right\rangle=D \cdot\left(-V_{O} / 2 R_{O}\right)+(1-D) \cdot\left(I-V_{o} / 2 R_{O}\right)=0$

Moreover,

$V_{g}-I R_{L}-I D R_{O n^{-}}(1-D) \cdot V_{D^{-2 I .(D-1) . R}} D^{-2(1-D) \cdot V_{D}}-(1-D) V_{o} / 2=0$

$I .(1-D)-\left(V o / 2 R_{O}\right)=0$

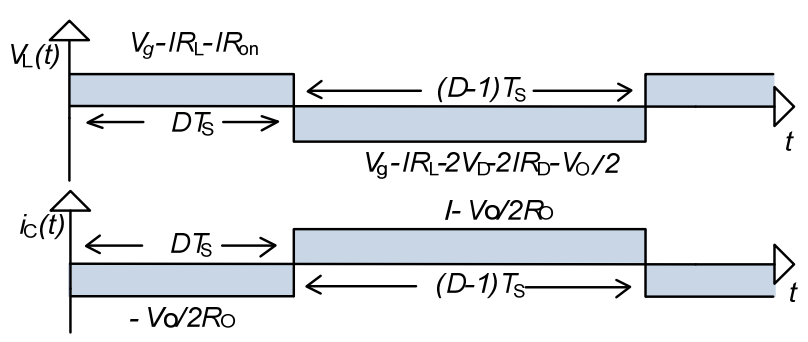

Fig. 6: Waveforms of inductor voltage and capacitor current in CCM for 2-stage switched capacitor boost based dc-dc converter.

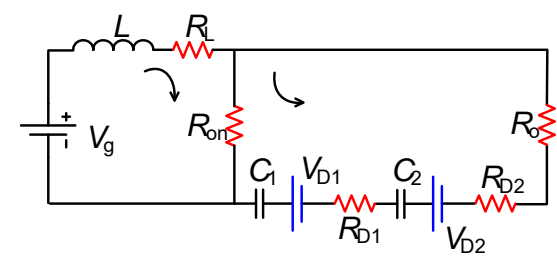

Fig. 7. 2-stage switched capacitor boost based dc-dc converter equivalent circuit for switch on state.

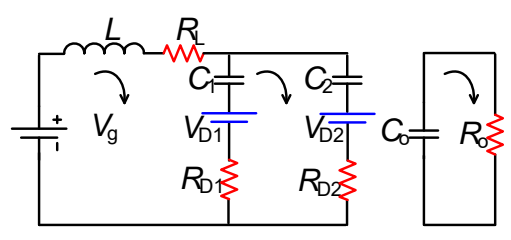

Fig. 8: 2-stage switched capacitor boost based dc-dc converter equivalent circuit for switch off state.

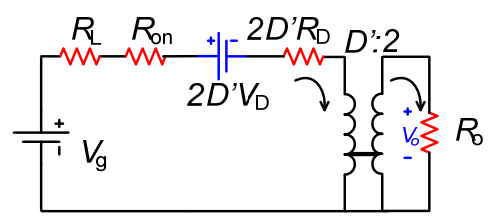

Fig. 9: 2-stage switched capacitor boost based dc-dc converter equivalent circuit.

It is easy to demonstrate that the static gain $M=V_{\mathrm{o}} / V_{\mathrm{g}}$ is given by:

$M=\frac{V_{O}}{V_{g}}=\left(\frac{2}{(1-D)}\right)\left(1-\frac{2(1-D) V_{D}}{V_{g}}\right)\left(\frac{1}{\left.1+\frac{R_{L}+D R_{O n}+2 R_{D}(1-D)}{(1-D)^{2} \cdot R_{O}}\right)}\right.$

Therefore, the efficiency is given by $\eta$ :

$\eta=(1-D) \frac{V_{C 1,2}}{V_{g}}$

According to equation (8):

$\eta=(1-D) \frac{V_{O}}{2 V_{g}}$

$\eta=\left(\frac{\left(1-\frac{2(1-D) V D}{V g}\right)}{1+\frac{R L+D R_{o n}+2 R_{D}(1-D)}{(1-D)^{2} \cdot R_{O}}}\right)$

\section{Results and Discussion}

In order to visualise the effect of parasitic elements on the converters, the variations of voltage gain and efficiency against duty cycle are plotted using MATLAB. For more realistic results, the values of the parasitic elements are selected based on actual components: $R_{\mathrm{DS}(\text { on) }}$ is $0.085 \Omega$ based on power switch IXTH $40 \mathrm{~N} 30, V_{\mathrm{D}}$ is $1.41 \mathrm{~V}$ for diode $30 \mathrm{CPF} 12 \mathrm{PbF}$, load is $R_{\mathrm{o}}=600 \Omega$ and $V_{\mathrm{g}}$ is $35 \mathrm{~V}$.

Figure 10(a) shows the gain verses duty ratio curve by plotting the gain equations (5) and (13) in MATLAB. Ideally, if no parasitic resistive elements $\left(R_{\mathrm{L}}=0, R_{\mathrm{o}}=600\right.$, $\left.R_{\mathrm{on}}=0, R_{\mathrm{D}}=0, V_{\mathrm{D}}=0\right)$ are considered, the addition of 2-stage 
$\mathrm{SC}$ to the basic boost converter offers a voltage gain higher than the conventional topology. However, it is clear from

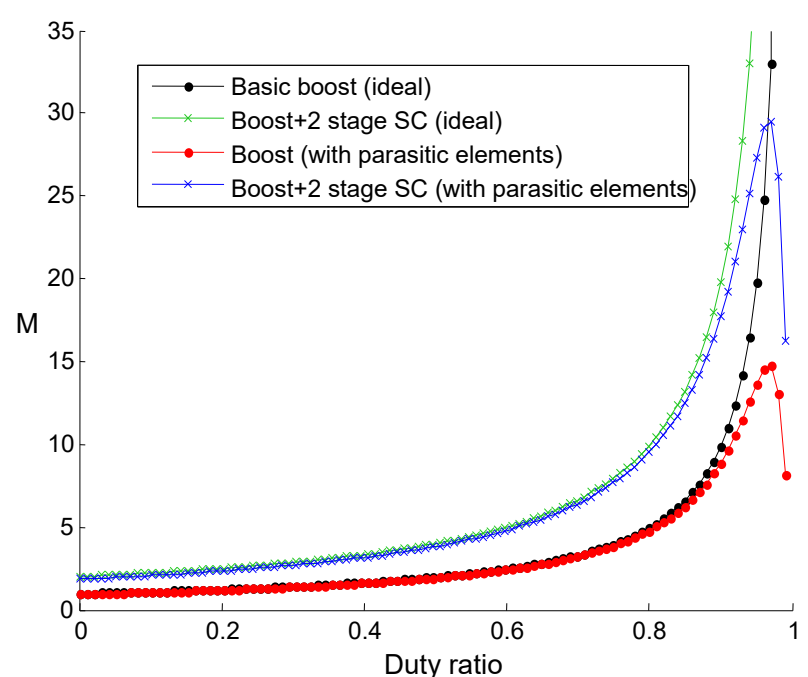

(a)

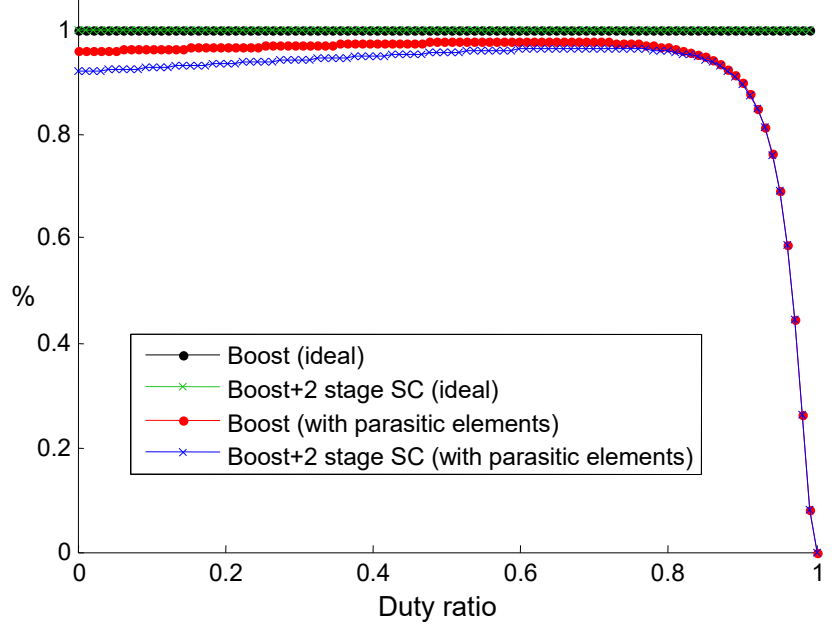

(b)

Fig. 10: (a) Voltage gain comparison (b) efficiency comparison.

Fig. 10 (a) that the parasitic resistive elements significantly affect the gain of both topologies. For non-ideal condition, the parasitic resistive elements considered are of value $\left(R_{\mathrm{L}}=0.6\right.$, $\left.R_{\mathrm{o}}=600, R_{\mathrm{on}}=0.085, R_{\mathrm{D}}=0, V_{\mathrm{D}}=1.41\right)$. As expected, the gain of the 2-stage SC boost based dc-dc converter remains approximately two times higher than the gain of the conventional boost converter, due to the voltage doubling effect. For values of the parasitic elements taken into consideration, the maximum voltage gain is limited to about 14.5 for basic boost. The use of SC effectively extended the gain to 30 .

In addition, Fig. 10 (b) provides an efficiency verses duty ratio curve by plotting the efficiency equations (7) and (16), in MATLAB. Ideally, if no parasitic resistive elements $\left(R_{\mathrm{L}}=0\right.$, $\left.R_{\mathrm{o}}=600, R_{\mathrm{on}}=0, R_{\mathrm{D}}=0, V_{\mathrm{D}}=0\right)$ are considered, their respective efficiency equations offer $100 \%$ efficiency for both converters. For non-ideal conditions, the efficiency of the conventional boost converter appears slightly above the boost converter with 2-stage SC. This is due to the fact that the addition of 2-stage SC adds parasitic elements resulting into slightly higher losses. However, the efficiencies for both converters are quite close to one another, and converge as the duty cycle increases. In general, the efficiencies of both converters are reasonably good for duty cycle below 0.8 , but quickly deteriorate as the duty cycle increases.

\section{Conclusion}

In this paper, the theoretical voltage gain and efficiency of a basic boost converter and a boost converter with 2-stage SC has been analyzed and compared. As expected, the voltage gain of the 2-stage SC based boost converter is higher than the basic boost converter for the same duty ratio, at the cost of lower efficiency. However if the objective is to obtain the same voltage gain, the 2-stage SC boost based converter gives the same gain at a lower duty ratio, resulting in compensation of efficiency with the basic boost converter. Even though the cost of a 2-stage SC based boost converter is higher than that of a basic boost converter, it allows the extension of the voltage gain that would otherwise not be practically viable with the basic boost. Furthermore, the difference in terms of efficiency for both converters is quite marginal, especially for practical duty in the range of 0.5-0.9. All this assures the suitability of SC-based boost-converter to replace basic boost converter for high voltage gain application.

\section{References}

1. Zhao, Q., et al. Active-clamp DC/DC converters using magnetic switches. in Applied Power Electronics Conference and Exposition, 2001. APEC 2001. Sixteenth Annual IEEE. 2001. IEEE.

2. $\quad$ Prudente, M., et al., Voltage multiplier cells applied to non-isolated DC-DC converters. IEEE Transactions on Power Electronics, 2008. 23(2): p. 871-887.

3. Park, K.-B., et al. Integrated boost-sepic converter for high step-up applications. in 2008 IEEE Power Electronics Specialists Conference. 2008. IEEE.

4. Seong, H.-W., et al. Novel dual inductor-fed DC-DC converter integrated with parallel boost converter. in 2008 IEEE Power Electronics Specialists Conference. 2008. IEEE.

5. Wai, R.-J. and R.-Y. Duan, High step-up converter with coupled-inductor. IEEE Transactions on Power Electronics, 2005. 20(5): p. 1025-1035.

6. Copple, E.J., High efficiency DC step-up voltage converter. 1999, Google Patents.

7. Amir, A., J. Selvaraj, and N. Rahim, Study of the MPP tracking algorithms: Focusing the numerical method techniques. Renewable and Sustainable Energy Reviews, 2016. 62: p. 350-371.

8. Iqbal, S., G.K. Singh, and R. Besar, A dual-mode input voltage modulation control scheme for voltage 
multiplier based X-ray power supply. IEEE Transactions on Power Electronics, 2008. 23(2): p. 1003-1008.

9. Zhou, D., A. Pietkiewicz, and S. Cuk, A three-switch high-voltage converter. IEEE Transactions on Power Electronics, 1999. 14(1): p. 177-183.

10. Sun, J., et al., Series resonant ZCS-PFM DC-DC converter with multistage rectified voltage multiplier and dual-mode PFM control scheme for medical-use high-voltage X-ray power generator. IEE Proceedings-Electric Power Applications, 2000. 147(6): p. 527-534.

11. Amir, A., S. Taib, and S. Iqbal. Voltage multiplierbased continuous conduction LCCL series resonant inverter fed high voltage $D C-D C$ converter. in Industrial Electronics and Applications (ISIEA), 2013 IEEE Symposium on. 2013. IEEE.

12. Tofoli, F.L., et al., Survey on non-isolated highvoltage step-up $d c-d c$ topologies based on the boost converter. IET Power Electronics, 2015. 8(10): p. 2044-2057.

13. Lee, S.S., S. Iqbal, and M. Kamarol, Control of ZCSSR inverter-fed voltage multiplier-based highvoltage $D C-D C$ converter by digitally tuning tank capacitance and slightly varying pulse frequency. IEEE transactions on power electronics, 2012. 27(3): p. 1076-1083.

14. Chen, Z., S. Liu, and L. Shi, A soft switching full bridge converter with reduced parasitic oscillation in a wide load range. Power Electronics, IEEE Transactions on, 2014. 29(2): p. 801-811.

15. Li, W. and X. He, Review of nonisolated high-stepup $D C / D C$ converters in photovoltaic gridconnected applications. IEEE Transactions on Industrial Electronics, 2011. 58(4): p. 1239-1250.

16. Wu, B., et al., A New Hybrid Boosting Converter for Renewable Energy Applications. Power Electronics, IEEE Transactions on, 2016. 31(2): p. 1203-1215.

17. Erickson, R.W., Steady-State Equivalent Circuit Modeling, Losses, and Efficiency, in Fundamentals of Power Electronics. 1997, Springer. p. 40-61.

18. Wu, G., X. Ruan, and Z. Ye, Nonisolated High StepUp DC-DC Converters Adopting SwitchedCapacitor Cell. Industrial Electronics, IEEE Transactions on, 2015. 62(1): p. 383-393. 